\title{
Clinical and Radiologic Outcomes of Volar Plate Fixation in AO Type C Distal Radius Fractures
}

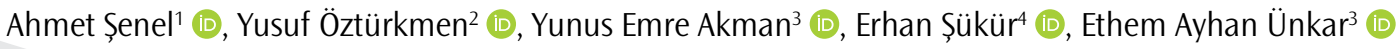

Introduction: To evaluate the clinical and radiological outcomes of anatomic volar plate application in AO type C distal radius fractures.

Methods: Patients who were operated on between January 2015 and April 2016 due to AO type C distal radius fracture were screened retrospectively from the hospital file and radiology archive. Clinical outcomes were determined by the disabilities of the arm, shoulder, and hand (DASH) score from outpatient records. The Stewart radiological scores were assessed with the measurements obtained from radiology archives. The complications were noted.

Results: Overall, 16 patients (mean age, 52 years) were included in the study. In total, 9 of the patients were female, and 7 of the patients were male. The mean follow-up period was 11.9 months. The mean DASH score was 33.9, and the mean Stewart radiological score was 0.9 . The bone union was accomplished in all patients. One infection, one joint stiffness, one carpal tunnel syndrome, and 2 tendinitis were observed as complication.

Conclusion: Volar plate fixation in the AO type C distal radius fractures provides satisfactory results in terms of either clinical or radiological outcomes. Despite that, the complications regarding surgery and the implants are not rare.

Keywords: Volar plate, distal radius, $\mathrm{AO}$ type $\mathrm{C}$

ORCID IDs of all authors: A.Ș. 0000-00027648-1504; Y.Ö. 0000-0002-2199-2411; Y.E.A. 0000-0003-2939-0519; E.Ș. 0000-0002-4697-7904; E.A.Ü. 0000-0002-0093-7886

${ }^{1}$ Clinic of Orthopedics and Traumatology, Elazı $\breve{g}$ Kovancılar State Hospital, Elazı̆̆, Turkey ${ }^{2}$ Depantment of Orthopedics and Traumatology, İstanbul Training and Research Hospital, İstanbul, Turkey

${ }^{3}$ Depantment of Orthopedics and Traumatology, Metin Sabancı Baltalimanı Kemik Hastalıkları Training and Research Hospital, İstanbul, Turkey ${ }^{4}$ Depantment of Orthopedics and Traumatology, Sakarya Training and Research Hospital, Sakarya, Turkey

Address for Correspondence:

Ahmet Şenel

E-mail: drahmetsenel@yahoo.com

Received: 22.12.2016

Accepted: 06.11.2017

(C) Copyright 2018 by Available online at istanbulmedicaljournal.org

\section{Introduction}

Distal radius fracture is one of the most common types of fractures, and it constitutes $25 \%$ of pediatric fractures and $18 \%$ of adult fractures (1). When examined by age, these fractures show a bimodal distribution (2). While it occurs due to high-energy trauma particularly in young patients, it occurs due to low-energy trauma in elderly patients ( $>65$ years) because of accompanying osteoporosis (3). Although distal radius fractures occurring due to high-energy trauma are seen more frequently in males than in females, the corrected incidence, according to the general age, is 4-5 times higher in females than in males (4).

In the Arbeitsgemeinschaft für Osteosynthesefragen (AO) classification, which is frequently used for distal radius fractures in practice, the " $C$ " subgroup has been defined for fractures involving the entire joint (5). In these types of fractures, it has been reported that the risks of improper bone knitting, joint non-compliance, and osteoarthritis are more frequent in non-surgical treatments than in surgical treatments in the long term (6). Currently, various surgical treatments, such as dorsal or volar plating, external fixation, bridge plating, and fragment-specific fixation, have been described for distal radius fractures (4). The superiorities, advantages, and disadvantages of all these methods have been the subject of many studies in the literature (6-10).

Herein, we aimed to evaluate the clinical outcomes of patients who underwent open reduction internal fixation and volar plating due to $\mathrm{AO}$ type $\mathrm{C}$ distal radius fractures.

\section{Methods}

Between January 2015 and April 2016, at our clinic, 16 patients who underwent volar plating due to distal radius intra-articular fracture were retrospectively searched in the hospital file records and radiology archives and included in the study. Our criteria for the inclusion in the study were that the patient must be over 20 years of age, his/her postoperative policlinic controls must have been made and clinical functions must have been evaluated, his/her radiological imaging must have been completed, his/her written and verbal consents must have been received, and he/she must have had a type $C$ fracture (multi-part fracture involving the entire joint) according to AO classification, which is not open and not accompanied by neovascular damage (Figure 1). Ethics committee approval was received for the study. 
The same surgical procedure was applied in all the patients. After general anesthesia, a pneumatic tourniquet was wrapped around the arm to be operated at an appropriate pressure, considering the patient's systolic blood pressure. After that, the upper extremity, up to the tourniquet including the hand, was cleaned with $10 \%$ polyvinylpyrrolidone iodine complex, and surgical antisepsis was provided. The patient was covered with a sterilized cover set. The skin was longitudinally opened over the flexorcarpiradialis (FCR) tendon. The FCR tendon was taken toward the radial side, and the pronator quadratus muscle was removed from the radial origin and deviated toward the ulnar side. The fracture zone was reached. After reduction was provided with temporary k-wires under scopic control, 2.7-mm anatomic distal radius locked volar plate (TST, Istanbul, Turkey) was fixed in the fracture site with 3.5 $\mathrm{mm}$ with locked screw (TST) (Figure 2). After plate fixation, k-wires were removed. The pronator quadratus muscle was again sutured to the radial origin. The tourniquet was removed, and bleeding was controlled. The skin was closed. After dressing, extremity immobilization was provided with a short-arm splint.

After the incision site was controlled and dressing was done, the patients were discharged on the $2^{\text {nd }}$ postoperative day. After discharge of the patients, second-generation cephalosporin prophylaxis (cephalexin) $2 \mathrm{gm} /$ day for 3 days was prescribed for prophylactic purposes. Doing finger exercises at home was suggested.

The patients were controlled for postoperative fracture reduction, and the sutures were removed on the $12^{\text {th }}$ postoperative day; the splint was removed on the $21^{\text {st }}$ day. Active joint motion exercises were initiated after splint removal. Consequently, through physical examination in the $1^{\text {st }}$, $3^{\text {rd }}$, and $6^{\text {th }}$-month controls, the questionnaire scores of disabilities of the arm, shoulder, and hand (DASH) were documented. Radiologic evaluation was performed with Stewart scoring using the anterior-posterior and lateral wrist radiographs (Figures 3 and 4).

\section{Statistical Analysis}

Statistical Package for Social Sciences 15.0 for Windows (SPSS Inc.; Chicago, IL, USA) was used for statistical analysis. Descriptive statistics are given as mean, standard deviation, minimum, and maximum for numerical variables. Because the normal distribution was provided, the numerical variables were compared with the Student's $\mathrm{t}$ test, and the ordinal variables were compared with the Mann-Whitney $\mathrm{U}$ test in the 2 independent groups. The relationships between the numerical variables were analyzed by Pearson correlation analysis when parametric test condition was provided and by Spearman correlation analysis when parametric test condition was not provided. Statistical significance level of alpha was accepted as $p<0.05$.

\section{Results}

Nine of the patients included in the study were female and 7 were male; the mean age was 52 years (range, 24-81 years). Eight patients were operated on the right side and 8 patients on the left side. The patients were followed up for 11.8 months on average (ranging from 6 to 21 months) (Table 1). It was found that the etiology was sports injuries in 3 of the patients, blunt injuries in 1, non-vehicle accident in 1, and a simple fall in 11. At the end of the follow-up period, the mean DASH score was measured as 33.9. At the end of the test, it was determined that all the fractures knitted. It was found that superficial infection (controlled by dressing and antibiotics) developed in 1 patient, joint stiffness in 1, carpal tunnel syndrome in 1 , and tendinitis in 2 . In the physical therapy clinic, rehabilitation sessions were started in the patients with tendinitis and joint stiffness. Loosening was achieved with surgical intervention in the patient in whom carpal tunnel syndrome developed.
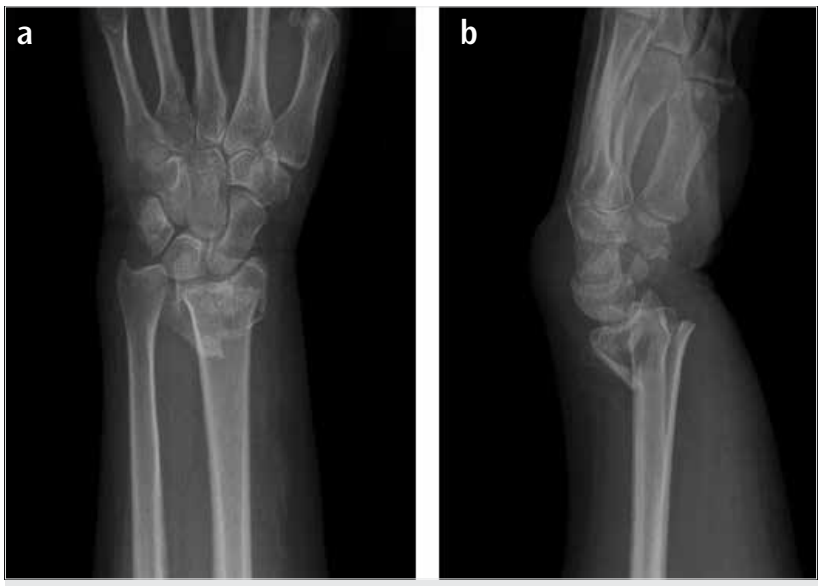

Figure 1. a, b. Anterior-posterior (a) and lateral radiography of the distal radius $\mathrm{AO}$ type $\mathrm{C}$ fracture $(\mathrm{b})$
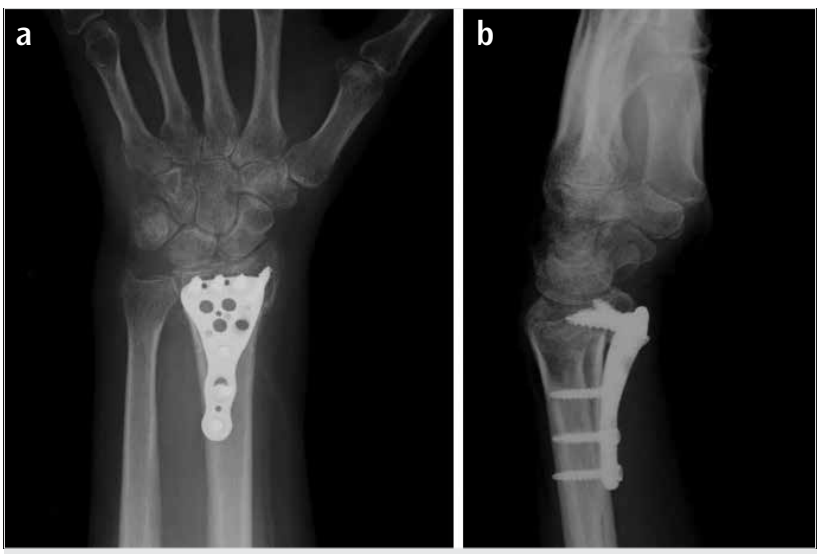

Figure 2. a, b. Anterior-posterior (a) and lateral radiography at the $3^{\text {rd }}$ month after volar plate application (b)
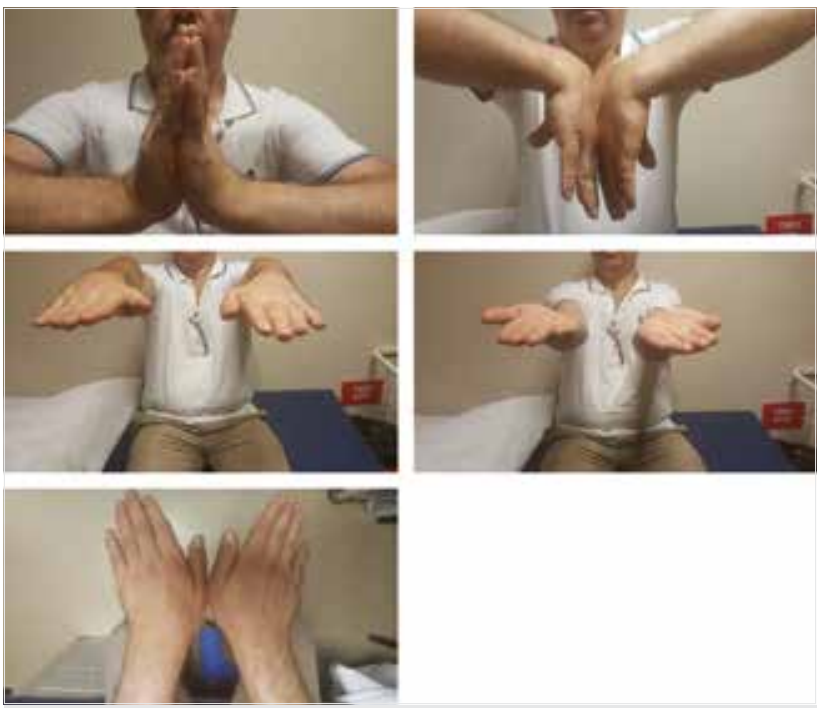

Figure 3. Clinical appearance of a 49-year-old male patient in the 6 th postoperative month 
In radiological evaluations, radial inclination and length, sagittal tilt, and radio-ulnar variance were evaluated based on the anteroposterior and lateral radiographs taken on the operated side. Mean radial inclination was found to be $16.2^{\circ}$, radial length $11.6 \mathrm{~mm}$, sagittal tilt $6.1^{\circ}$, and radio-ulnar variance $0.7 \mathrm{~mm}$. The Stewart radiological evaluation score was found to be 0.9 (11). According to the Stewart radiological evaluation score, excellent results were obtained in 4 (25\%) patients and good results in 12 (75\%).
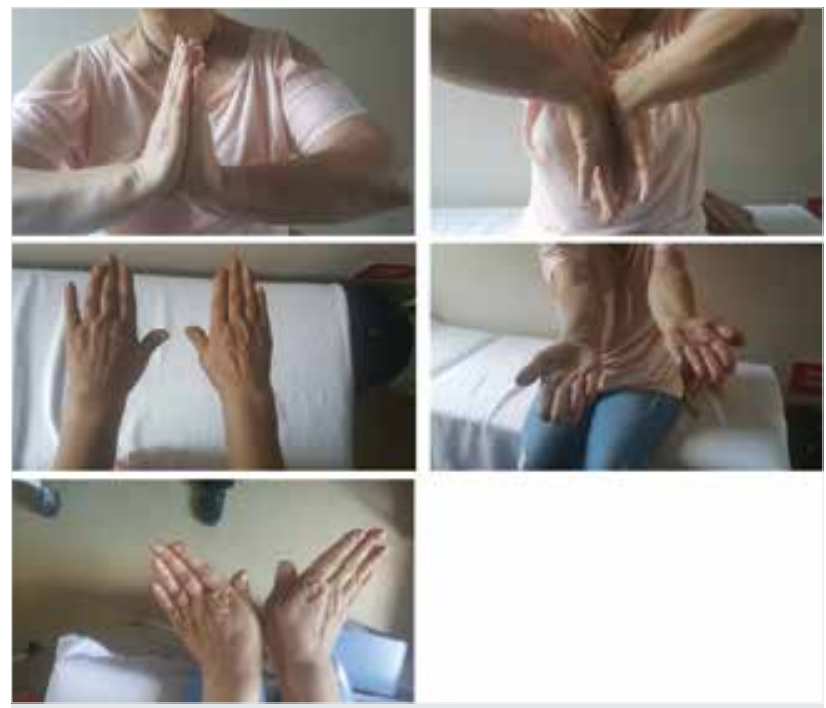

Figure 4. Clinical appearance of a 60-year-old female patient in the 6th postoperative month

\section{Discussion}

Today, anticipated life span prolongation, increased motor vehicle and traffic intensity, and widespread sport activities have increased the frequency of distal radius fractures. Considering the fact that the number of females was higher than that of males in our study population and considering the etiologic factors causing the fracture, it was seen that high-energy trauma in young persons and low-energy trauma in the elderly were the causes of fractures. In the literature, many regionally conducted epidemiological and etiological studies also show consistency with our findings (11-13).

Casting is still the mainstay of treatment in stable and unstable distal radius fractures. However, casting in fractures that are intra-articular and in cases with metaphyseal bone loss may cause joint instability (14). The treatment of distal radius fractures with volar plates has become increasingly popular over the past decade. Advantages such as acquisition of early joint movements, quick start of mobilization, and acquisition of biomechanically stable fixation are facilitated with this method (15-16). Sharma et al. (6) have compared volar plate application with non-surgical treatments in $\mathrm{AO}$ types $\mathrm{B}$ and $\mathrm{C}$ distal radius fractures. In particular, they reported that functional scores are better in patients treated with volar plates. The functional outcomes (DASH score) obtained in the patients in our study also support those in the literature.

In many studies, it has been reported that there is no correlation between radiological results and functional outcomes $(9,17$, 18). In contrast, radiographic findings in volar plate application have been found to be better (19). In the study conducted in 122 patients who underwent surgical treatment, Letsch et al. (20) re-

Table 1. Overall distribution of the findings of the patients

\begin{tabular}{|c|c|c|}
\hline Age Mean $\pm S D$ (Min-Max) & & $52.1 \pm 16.5 / 24-81$ \\
\hline \multirow[t]{2}{*}{ Gender n (\%) } & Male & $7(43.8)$ \\
\hline & Female & $9(56.3)$ \\
\hline \multirow[t]{2}{*}{ Side $n(\%)$} & Left & $8(50.0)$ \\
\hline & Right & $8(50.0)$ \\
\hline Follow-up duration (month) Mean \pm SD (Min-Max) & & $11.8 \pm 5.1 / 4-21$ \\
\hline Radial inclination Mean \pm SD (Min-Max) & & $16.2 \pm 3.2 / 13-24$ \\
\hline Radial length Mean $\pm S D$ (Min-Max) & & $11.6 \pm 2.1 / 7.4-14.9$ \\
\hline Palmar tilt Mean \pm SD (Min-Max) & & $6.1 \pm 4.1 / 0-13$ \\
\hline Ulnar variance Mean \pm SD (Min-Max) & & $0.71 \pm 1.53 /-1.8-3$ \\
\hline DASH score Mean \pm SD (Min-Max) & & $33.9 \pm 7.1 / 20.7-44.8$ \\
\hline \multirow[t]{5}{*}{ Complication n (\%) } & & $5(31.3)$ \\
\hline & Tendinitis & $2(12.5)$ \\
\hline & CTS & $1(6.3)$ \\
\hline & Joint stiffness & $1(6.3)$ \\
\hline & Superficial infection & $1(6.3)$ \\
\hline Stewart Score Mean \pm SD (Min-Max) & & $0.94 \pm 0.77 / 0-3$ \\
\hline \multirow[t]{2}{*}{ Results of Stewart Scores n (\%) } & Good & $12(75.0)$ \\
\hline & Excellent & $4(25.0)$ \\
\hline
\end{tabular}


Table 2. There was no statistical significance between DASH and Stewart scores and patient age

\begin{tabular}{lcc} 
& \multicolumn{2}{c}{ Age } \\
\cline { 2 - 3 } & \multicolumn{1}{c}{ R } & p \\
\hline DASH score & 0.454 & 0.077 \\
Stewart Score & 0.024 & 0.930 \\
\hline DASH=Disabilities of the arm, shoulder, and hand &
\end{tabular}

Table 3. There was no statistical significance between DASH and Stewart scores and gender

\begin{tabular}{lccc} 
& \multicolumn{3}{c}{ Gender } \\
& $\begin{array}{l}\text { Male } \\
\text { Mean } \pm \text { SD }\end{array}$ & $\begin{array}{c}\text { Female } \\
\text { Mean } \pm \text { SD }\end{array}$ & p \\
\hline DASH score & $32.9 \pm 6.8$ & $34.7 \pm 7.7$ & 0.624 \\
Stewart Score & $1.00 \pm 1.00$ & $0.89 \pm 0.60$ & 0.951 \\
\hline DASH: disabilities of the arm, shoulder, and hand; SD: standard deviation
\end{tabular}

\section{Table 4. No correlation was found between Stewart score} and DASH score

\begin{tabular}{lcc} 
& \multicolumn{2}{c}{ DASH score } \\
\cline { 2 - 3 } & rho & p \\
\hline Stewart skoru & 0.259 & 0.332 \\
\hline DASH: disabilities of the arm, shoulder, and hand & &
\end{tabular}

ported that they obtained excellent-good results at a rate of $90 \%$ in the Stewart scoring assessment. In our study, the radiological measurements obtained in the postoperative period were within the range of acceptable values, the clinical findings did not correlate with the radiological findings (Table 2-4), and the Stewart scoring supported the literature.

Although the use of volar plates for distal radius fractures has recently gained popularity, high complication rates up to $27 \%$ have been reported in the literature. These complications include not knitting of the bones, carpal tunnel syndrome, tendinitis and tendon rupture, infection, finger stiffness, wrist and elbow pain, and implant-related problems $(19,21,22)$. We think that the higher rate of complications found in our study in comparison to that reported in the literature (31\%) was caused by the small number of cases included in the study.

The limitation of the present study is the small number of patients. The literature should be supported with more case series.

\section{Conclusion}

Non-surgical treatments of joint-related AO type C distal radius fractures pose a risk of joint instability. Because of this, surgical treatment options, and particularly volar plate application, are becoming more and more preferred by day. The results of treatment with volar plate are satisfactory in terms of both clinical and radiological outcomes. However, care must be taken in terms of the complications that may occur due to fracture anatomy and
Ethics Committee Approval: Ethics committee approval was received for this study from the ethics committee of istanbul Training and Research Hospital (Approval Date: 09.12.2016; Approval Number: 892).

Informed Consent: Written and verbal informed consent was obtained from the patients who participated in this study.

Peer-review: Externally peer-reviewed.

Author Contributions: Concept - A.Ş, E.Ş.; Design- Y.E.A., E.A.Ü.; Supervision - Y.Ö., E.Ş.; Data Collection and/or Processing - A.S., E.A.Ü.; Analysis and/or Interpretation - Y.Ö., Y.E.A., E.S..; Literature Search - E.S.., E.A.Ü., A.S.; Writing - A.S.; Critical Reviews - Y.Ö., Y.E.A., E.S.

Conflict of Interest: The authors have no conflicts of interest to declare.

Financial Disclosure: The authors declared that this study has received no financial support.

\section{References}

1. Nellans KW, Kowalski E, Chung KC. The epidemiology of distal radius fractures. Hand Clin 2012; 28: 113-25. [CrossRef]

2. Alluri RK, Hill JR, Ghiassi A. Distal Radius Fractures: Approaches, Indications, and Techniques. J Hand Surg Am 2016; 41: 845-54. [CrossRef]

3. Koo KOT, Tan DMK, Chong AKS. Distal radius fractures: an epidemiological review. Orthop Surg 2013; 5: 209-13. [CrossRef]

4. Brogan DM, Richard MJ, Ruch D, Kakar S. Management of severely comminuted distal radius fractures. J Hand Surg Am 2015; 40: 1905-14. [CrossRef]

5. Muller ME, Nazarian S, Koch P, Schatzker J. The comprehensive classification of fractures of longbones. Berlin, Germany: Springer-Verlag 1990; 100-1. [CrossRef]

6. Sharma H, Khare GN, Singh S, Ramaswamy AG, Kumaraswamy V, Singh AK. Outcomes and complications of fractures of distal radius (AO type $\mathrm{B}$ and $\mathrm{C}$ ): volar plating versus nonoperative treatment. J Orthop Sci 2014; 19: 537-44. [CrossRef]

7. Sammer DM, Fuller DS, Kim HM, Chung KC. A comparative study of fragment-specific versus volar plate fixation of distal radius fractures. Plast Reconstr Surg 2008; 122: 1441-50. [CrossRef]

8. Shukla R, Jain RK, Sharma NK, Kumar R. External fixation versus volar locking plate for displaced intra-articular distal radius fractures: a prospective randomized comparative study of the functional outcomes. J OrthopTraumatol 2014; 15: 265-70. [CrossRef]

9. Disseldorp DJ, Hannemann PF, Poeze M, Brink PR. Dorsal or Volar Plate Fixation of the Distal Radius: Does the Complication Rate Help Us to Choose? J Wrist Surg 2016; 05: 202-10. [CrossRef]

10. Stewart HD, Innes AR, Burke FB. Factor affecting the outcome of Colles' fracture: an anatomical and functional study. Injury. 1985; 16: 289-95. [CrossRef]

11. Flinkkila T, Sirnio K, Hippi M, Hartonen S, Ruuhela R, Ohtonen P, et al. Epidemiology and seasonal variation of distal radius fractures in Oulu, Finland. Osteoporos Int 2011; 22: 2307-12. [CrossRef]

12. Sigurdardottir K, Halldorsson S, Robertsson J. Epidemiology and treatment of distal radius fractures in Reykjavik, Iceland, in 2004. Comparison with an Icelandic study from 1985. Acta Orthop 2011; 82: 494-8. [CrossRef]

13. Court-Brown CM, Caesar B. Epidemiology of adultfractures: A review. Injury 2006; 37: 691-7. [CrossRef]

14. Orbay JL, Badia A, Indriago IR, Infante A, Khouri RK, Gonzalez E, et al. The extended flexorcarpiradialis approach: a new perspective for the distal radius fracture. Tech Hand Up Extrem Surg 2001; 5: 204-11. [CrossRef]

15. Chung KC, Watt AJ, Kotsis SV, Margaliot Z, Haase SC, Kim HM. Treatment of unstable distal radial fractures with the volar locking plating system. J Bone Joint Surg Am 2006; 88: 2687-94 [CrossRef]

16. Cooper EO, Segalman KA, Parks BG, Sharma KM, Nguyen A. Biomechanical stability of a volar locking-screw plate versus fragment-specif- 
ic fixation in a distal radius fracture model. Am J Orthop (Belle Mead NJ) 2007; 36: 46-9

17. Young CF, Nanu AM, Checketts RG. Seven-year outcome following Colles' type distal radial fracture. A comparison of two treatment methods. J Hand Surg Br 2003; 28: 422-6. [CrossRef]

18. Fujii K, Henmi T, Kanematsu Y, Mishiro T, Sakai T, Terai T. Fractures of the distal end of radius in elderly patients: a comparative study of anatomical and functional results. J Orthop Surg (Hong Kong) 2002; 10: 9-15. [CrossRef]

19. Arora R, Lutz M, Hennerbichler A, Krappinger D, Espen D, Gabl M. Complications following internal fixation of unstable distal radius fracture with a palmar locking-plate. J Orthop Trauma 2007; 21: 316-22. [CrossRef]
20. Letsch R, Infanger M, Schmidt J, Kock HJ. Surgical treatment of fractures of the distal radius with plates: a comparison of palmar and dorsal plate position. Arch Orthop Trauma Surg 2003; 123: 333-9. [CrossRef]

21. Rozental TD, Blazar PE. Functional outcome and complications after volar plating for dorsally displaced, unstable fractures of the distal radius. J Hand Surg Am 2006; 31: 359-65. [CrossRef]

22. Drobetz H, Kutscha-Lissberg E. Osteosynthesis of distal radial fractures with a volar locking screw plate system. Int Orthop 2003; 27: 1-6.

Cite this article as: Şenel A, Öztürkmen Y, Akman YE, Şükür E, Ünar EA. Clinical and Radiologic Outcomes of Volar Plate Fixation in AO Type C Distal Radius Fractures. İstanbul Med J 2018; 19: 119-23. 